\title{
EL FEMICIDIO COMO DELITO Y FALSO INSTRUMENTO DE PREVENCIÓN: LECTURA HISTÓRICA, SOCIO JURIIDICA Y POLÍTICA ${ }^{1}$
}

\author{
Diego Germán Benavídez NarváEZ ${ }^{2}$ \\ FISCALÍA GENERAL DEL ESTADO, QUITO - ECUADOR
}

\section{RESUMEN:}

La tipificación del femicidio no ha reducido la muerte de mujeres, como tampoco ha permitido evidenciar qué mecanismos penales, tales como la prevención específica y general, sean eficaces. A esto se suma que de un tiempo acá, el sistema jurídico ecuatoriano se encuentra imbuido por un populismo penal creciente, el cual sostiene que la creación de nuevos delitos y el endurecimiento de penas son las mejores herramientas para tratar un problema tan complejo como lo es la violencia contra la mujer; las estadísticas así lo demuestran: el número de casos de femicidio en el Ecuador han ido en aumento desde su tipificación, lo cual hace evidente que su inclusión, como delito en el campo penal, ha sido una cortina de humo, que disfraza y oculta una total falacia, tanto jurídica, como estadística que termina perjudicando justamente a quienes se busca defender: LAS MUJERES.

1 Artículo recibido el 4 de noviembre de 2019 y aprobado el 28 de noviembre de 2019

2 Abogado de los tribunales y juzgados de la República del Ecuador ORCID: 0000-0003-0450-0822 


\section{PALABRAS CLAVE:}

Femicidio/feminicidio, prevención general, Derecho penal del enemigo, falacias jurídicas

\section{ABSTRACT:}

The definition of femicide has not reduced the death of women, nor has it allowed evidence that criminal mechanisms, such as general prevention, are effective. To this, is added the conjunctural moment that the Ecuadorian legal system has been going through for several years: criminal populism is growing and it argues that the creation of new crimes and the hardening of sentences are the best tools to address such a complex and structural problem, as is violence against women. Statistics show that, the number of cases of femicide in Ecuador has been increasing since its classification, which makes it clear that its inclusion as a crime in the criminal field has been a smoke screen, that disguises and conceals a total fallacy, both legally and statistically, that ends up harming precisely those who seek to defend: WOMEN.

\section{KEYWORDS:}

Femicide, general prevention, criminal right of the enemy, legal falacies 


\section{INTRODUCCIÓN:}

En muchas ocasiones es más fácil ignorar un problema, antes que analizarlo, tratarlo y luego resolverlo, circunstancia que se agrava aún más, si dicho problema se deriva de un conflicto social, que tiene una base netamente estructural como es la violencia intrafamiliar, y si a esto se le añade una aparente soluciónrespuesta, originada desde el ámbito penal, se tiene literalmente un producto convertido en tipo penal, denominado en el Ecuador como femicidio.

Si bien es cierto que en la sociedad ecuatoriana la violencia contra la mujer es un tema real y lo más alarmante es que éste va en aumento, sin embargo, la alternativa que se ha propuesto, desde el actual feminismo como respuesta para tratarlo, no ha sido la mejor o, a su vez, no ha sido la más eficiente.

El tipificar el femicidio como delito, hasta el momento, no ha reducido la muerte de mujeres, ni tampoco ha permitido evidenciar que mecanismos penales, tales como la prevención específica y la prevención general, estén funcionando como se esperaba.

Por otro lado, los medios de comunicación e, incluso, aunque suene un poco atrevido, desde el mismo Estado, se proyecta constantemente la idea de que la creación de nuevos delitos es la mejor herramienta para la construcción de una sociedad más segura; supuesto que al parecer, choca frontalmente con la realidad y que quizá no va más allá de ser una oferta venida desde un populismo penal creciente.

Dicho populismo utiliza al poder punitivo como una respuesta reaccionaria para abordar el problema y se convierte, además, en 
un atajo, que le permite al Estado evitarse el engorroso y lento trabajo de enfocarse en opciones prácticas, reales y eficaces que permitan la disminución de la violencia no solamente contra las mujeres, sino contra todos en general.

Al respecto, es importante resaltar que en el delito de femicidio, en muchos de los casos se genera un efecto espejo de violencia entre agresor y víctima, puesto que las estadísticas reflejan un porcentaje considerable de casos en el que el hombre-agresor, luego de cometer el asesinato, éste decide también acabar con su vida, circunstancia que hace muy peculiar a este delito.

Por otra parte, en varios países centroamericanos y también del Cono Sur, actualmente existen leyes específicas en contra del femicidio, mientras que en otros países, por ejemplo, el Ecuador, se ha colocado al femicidio como un tipo penal específico, dentro de la norma sustantiva penal; sin embargo, desde la doctrina jurídica y crítica, la creación y tipificación de dicho delito se lo ha llegado a relacionar íntimamente con el Derecho penal del enemigo, puesto que quizás a quien se busca sancionar no es a un sujeto activo de la infracción en general, sino que existe implícita una cualificación dirigida y exclusiva hacia el hombre.

Finalmente, es importante resaltar que luego de más de cinco años de haber entrado en vigencia el COIP y, por ende, empezar a sancionar este delito en el país, poco o casi nada esto ha ayudado a prevenirlo. Si bien es cierto que cada año se ha judicializado y sancionado a muchos hombres y de manera exclusiva como autores de femicidio, lamentablemente, las muertes de mujeres han seguido incrementándose de manera progresiva estos últimos años. 


\section{La génesis del término femicidio}

En su historia se encuentran palabras utilizadas desde la antigüedad para denominar la muerte de mujeres, entre ellas, se han registrado feminicidio, femigenocidio, ginocidio o generocidio.

DiANA RUSSELL es la autora mayormente reconocida por ser quien utiliza y divulga el término inglés «femicide»; sin embargo, ella reconoce que no es su creadora, ya que anteriormente habría sido ya utilizado, e incluso menciona, en una de sus investigaciones, que la idea de expresar la muerte referida exclusivamente de mujeres, mediante la utilización de una palabra, se remonta al siglo XIX, precisamente al año 1801, en la obra: A Satirical View of London at the Commencement of the Nineteenth Century ${ }^{3}$.

Diana Russell y Jane CaPuti ponen en conocimiento al mundo entero el término femicide en el artículo Speaking the Unspeakable, publicado originalmente en la Revista Ms., en el año 1990, en donde se lo define como: el asesinato de mujeres realizado por hombres, motivado por odio, desprecio, placer o un sentido de propiedad de las mujeres ${ }^{4}$.

En publicaciones posteriores, RUSSELL agrega al concepto de femicide, a más de la descripción del asesinato de mujeres por hombres, incluye como particularidad el hecho de ser mujeres, esto en lugar de continuar con lo que sostenía CAPUTI, quien se centraba particularmente en la cuestión del odio. Ésta es la definición que se ha mantenido hasta ahora.

\footnotetext{
3 Russell, D. 2001, p. 13.

4 Ídem. 1990, pp. 34-37.
} 
Russell, en su libro Preface, desarrolla posteriormente el concepto de femicide, manifestando que: Es el asesinato de mujeres por el hecho de ser mujeres, siempre y cuando ese asesinato sea cometido por hombres ${ }^{5}$. Asimismo, CAPUTI junto con RUSSELL, en esta misma obra, lo describen así: La forma más extrema de terrorismo sexista, motivado por el odio, el desprecio, el placer o el sentimiento de propiedad hacia las mujeres ${ }^{6}$.

Al llamarlo femicide, consideran estas autoras que se está levantando el velo de los términos neutrales (nongendered terms) como el homicidio o el asesinato ${ }^{7}$.

Posteriormente, RuSSELl nuevamente lo redefine, pero ya no con el acompañamiento de CAPUTI, sino ahora lo realiza con otra feminista, llamada JILL RADFORD, definiéndolo como el asesinato misógino de mujeres cometido por hombres ${ }^{8}$.

Las dos autoras, creadoras de la obra The Politics of Woman Killing, clasifican y distinguen varias formas de violencia de género que padecen las mujeres, la cual desemboca, según su criterio, en lo que ellas denominan un terrorismo sexual creciente. Además, en su libro señalan varias categorías de violencia, entre las cuales el femicide se puede dar, indicando que éste representa el extremo de un continuиm de terror anti-femenino, que incluye una amplia variedad de abusos verbales y físicos, tales como: violación, tortura, esclavitud sexual -particularmente por prostitución-, abuso sexual infantil incestuoso o extra-familiar,

\footnotetext{
5 Russell, D. 1992, p. 14.

$6 \quad$ Ibíd. p. 15.

7 Ibíd.

8 RADFORD, J., y RuSSELL, D. 1992.
} 
golpizas físicas y emocionales, acoso sexual -por teléfono, en las calles, en la oficina y en el aula-, mutilación ${ }^{9}$.

Es así que en razón de todo lo anteriormente expuesto, se puede mencionar que, si bien es cierto que el término femicide, propuesto originalmente por RUSSELL, ha venido cambiando y de algún modo se podría decir ha evolucionado, sin embargo y desde sus orígenes, se hace evidente la disyunción extrema, entre la víctima-mujer y el victimario-hombre, teniendo siempre como vínculo de disyunción, entre estos dos sujetos, el aparente odio, desprecio, placer o un sentido de propiedad existente en el hombre hacia la mujer, a tal punto que serían precisamente estos sentimientos, el motor y los factores que incitan a él para que acabe con la vida de ella.

En el mismo sentido, no se puede desconocer la influencia que desde la génesis del femicide hasta ahora ha tenido la frase por el hecho de ser mujer, a tal punto que actualmente es un cliché feminista y mediático, sin embargo, desde lo gramatical, lo semántico y lo literal e incluso de acuerdo a como se encuentra tipificado hoy en el CoIP, en el ámbito jurídico penal, resulta extremadamente complicado el atreverse a concebir una definición, en estricto sentido, de lo que dicha frase significa, dato importante y a tomar en cuenta a posteriori, puesto que en el campo penal, las interpretaciones están absolutamente prohibidas y atentan al principio rector de este campo como es el principio de legalidad.

9 RAdFord, J. y Russell, D. 1992. 


\section{El concepto de femicide en América Latina}

El femicide como término de origen inglés y, por ende, derivado de la cultura anglosajona ha traído para Centro y Sudamérica una gran particularidad, la cual desemboca en el momento de su traducción, puesto que varias autoras feministas mayormente centroamericanas lo traducen y lo definen como femicidio; otras, en cambio, defienden que su correcta traducción es feminicidio; mientras que hay un grupo que sostiene que tanto la primera como la segunda traducción son conceptos, que existen de manera independiente, pero que se encuentran interrelacionados de manera causalista dentro del tema.

Es así que en México, uno de los países del denominado triángulo norte o corredor de la muerte han sido dos las escritoras y activistas, que han puesto sobre la mesa la muerte de mujeres en Ciudad Juárez, frontera norte de dicho país.

La primera de ellas es la antropóloga, política y feminista Marcela Lagarde, quien sigue la línea teórica de Diana RusSEll, por lo tanto, acepta la definición propuesta por ella, respecto a que el femicide es el asesinato misógino de mujeres exclusivamente por hombres; LAGARDE le añade la característica de impunidad estatal, existente, a su criterio, en la investigación y sanción de la muerte de mujeres, en manos de bandas delincuenciales, dedicadas al narcotráfico y a la trata de personas. En el mismo sentido y a su criterio, la traducción correcta del término femicide debería ser: Feminicidio porque en Castellano femicidio es una voz homóloga a homicidio y sólo significa asesinato de mujeres ${ }^{10}$.

10 Disponible en la siguiente página web: http://www.mujeresenred. 
En el pensamiento de LAGARDE, ella concibe al feminicidio como un concepto específico, por lo que en su paso por el Congreso mexicano como diputada, propuso la creación de un tipo penal específico para su sanción, puesto que según ella: el feminicidio está caracterizado por dos dimensiones: se trata de un crimen de género, misógino, de odio hacia las mujeres, que goza de una gran tolerancia social; y el Estado juega un gran papel en su impunidad, lo cual constituiría una de sus principales características ${ }^{11}$.

En efecto, y parafraseando a LAGARDE, es el Estado el que tiene responsabilidad en la prevención, tratamiento y protección de las mujeres ante la violencia de género y, por ende, debe garantizar la libertad y la vida de las mujeres.

Para Atencio, la ausencia de sanciones y de castigo a los asesinos coloca al Estado como responsable, por acción u omisión, del feminicidio y éste tiene que asumir su complicidad, o responsabilidad directa ${ }^{12}$.

La segunda escritora mexicana y activista en el tema es la socióloga Julia MonárRez, quien ha aportado instrumentos de análisis, documentos y registros de diversos tipos de feminicidio: feminicidio íntimo, a su vez, subdividido en infantil y familiar; feminicidio sexual sistémico, subdividido en organizado y desorganizado; y, feminicidio por ocupaciones estigmatizadas, información enfocada a hacer evidente la impunidad estatal y la omisión de las autoridades frente al aumento del narcotráfico en Ciudad Juárez.

net/spip.php?article141. (última consulta el 1 de noviembre de 2019)

Devineau, J. 2012, p. 54.

12 Atencio, G. 2011, p. 3. 
Su principal aporte ha sido el haber obtenido respuestas teóricas y prácticas sobre los crímenes de mujeres y niñas con la creación de la Base de Datos Feminicidio 1993-2005 ${ }^{13}$.

Al respecto, es importante mencionar que con dicha base de datos se permitió diferenciar los feminicidios de los asesinatos de mujeres, puesto que tal como sostiene Russell: El género femenino de una víctima es irrelevante para el perpetrador. Por ejemplo, un varón armado que dispara y mata a los propietarios, hombre y mujer, de un supermercado en el transcurso de su crimen, no ha cometido un feminicidio ${ }^{14}$.

Por otro lado, en Costa Rica, investigadoras sobre la violencia contra las mujeres, tales como Montserrat SAGot y AnA CARCEDo, al igual que toda una serie de activistas han preferido la utilización de la traducción y el concepto de femicidio para adoptar la elección inicial de RUSSEL y RADFORD ${ }^{15}$.

Es así que a ciencia cierta y hasta el día de hoy, no se tiene un común acuerdo de cuál es la correcta traducción del concepto femicide al Castellano, sin embargo, la mayor parte del movimiento feminista actual sostiene y defiende la existencia de una clara diferenciación entre femicidio y feminicidio.

Cabe indicar que se manifiesta que el femicidio es el término con el que mejor se describe todos aquellos asesinatos de mujeres, por parte de hombres, por razones de odio, placer o porque sienten algún tipo de propiedad sobre ellas, es decir, está cargado de un

\footnotetext{
13 MonÁRreZ, J. 2010.

14 Russel, D. 2016, p. 33.

15 SAgot, M., y Carcedo, A. 2002.
} 
proceso de violencia previa, que puede ser física, psicológica o sexual y que termina en asesinato, por tanto, siempre se da en las relaciones desiguales, entre hombres y mujeres, específicamente por razones de género ${ }^{16}$.

En el feminicidio, en cambio, se introduce la variable de impunidad detrás de los crímenes de femicidio, es decir, es la desprotección estatal hacia la mujer, por tanto, si el femicidio es un término que visibiliza el homicidio por razones de género, el feminicidio responsabiliza al Estado por ser quien favorece la impunidad de estos hechos.

\section{El contexto social de Ciudad Juárez}

No se conoce de manera cierta el número de mujeres que han sido asesinadas en Ciudad Juárez, en manos de los grupos, bandas, pandillas y cárteles, todos relacionados con el narcotráfico y su disputa por controlar la zona de frontera entre México y Estados Unidos; sin embargo, se estima que entre todas las mujeres víctimas, predominan factores sociales en común: casi todas pertenecen a una clase social baja y muchas de ellas trabajaban en las maquiladoras (empresas manufactureras mexicanas), conocidas por sus condiciones de precarización con mano de obra barata y explotación laboral.

Es indispensable, en este punto, resaltar que en locaciones como Ciudad Juárez, aún existe la diferenciación salarial entre hombres y mujeres, puesto que el estatus social femenino es inferior, razón por la que las empresas se aprovechan de ello y contratan

16 Mulier. "Feminismo", 22 de noviembre de 2018. Disponible en la siguiente página web: www.youtube. com. 
a mujeres trabajadoras, con la finalidad de pagarles un salario mucho más bajo ${ }^{17}$.

Dicha diferenciación laboral y salarial habría conseguido que la mano de obra femenina sea mayormente requerida para ser contratada y explotada, haciendo indirectamente que las oportunidades de empleo para los hombres en esa localidad se vuelvan escasas, trayendo quizá consigo un cambio coyuntural en la dinámica social y, posiblemente, creando una nueva causa de conflicto entre los sexos.

Muchos creen que los feminicidios de Juárez son crímenes organizados, y tal vez el retroceso patriarcal en los nuevos roles de género fue el punto de inflexión ${ }^{18}$.

\section{La condena de la Corte Interamericana de Derechos Humanos al Estado mexicano}

Es de vital importancia abordar el caso popularmente conocido como Campo Algodonero, por cuanto se trata de una sentencia histórica, de 167 hojas, emitida por la Corte Interamericana de Derechos Humanos (CIDH), en la cual se condena por primera vez al Estado mexicano por su acción, omisión y falta de diligencia en las investigaciones relacionadas, tanto en la desaparición de tres mujeres mexicanas, como en su posterior muerte; quizás lo más importante de dicha sentencia es que se la puede considerar como la génesis jurisprudencial y base para el posterior desarrollo del

17 "Feminicidios en Ciudad Juárez", Revista Muy Interesante. edición digital. (última consulta el 2 de noviembre de 2019). digital. (última consulta el 2 de noviembre de 2019) 
tema de feminicidios (como se lo denomina en México) a nivel internacional.

El caso de Campo Algodonero suscitó en Ciudad Juárez, lugar donde, como se menciona anteriormente, predomina el narcotráfico, la migración ilegal, la trata de personas y, sobretodo, la delincuencia organizada. Es así que desde la década de los noventa, ha existido un incremento de asesinatos de mujeres, motivados por una cultura de discriminación en su contra; reflejada en un patrón de violencia sistemática, puesto que las víctimas desaparecen, sin rastro alguno o, a su vez, cuando sus cadáveres son encontrados, se evidencian signos de tortura y violencia sexual, previa al arrojamiento de los cuerpos en el desierto o en lugares públicos.

Campo Algodonero hace referencia a la desaparición y posterior muerte de dos adolescentes y una mujer adulta, las tres de nacionalidad mexicana:

1) Laura Ramos, de 17 años de edad, de ocupación estudiante, quien desapareció el 22 de septiembre de 2001;

2) Esmeralda Herrera, de 15 años de edad, de ocupación empleada doméstica, desaparecida el lunes 29 de octubre de 2001; y,

3) Claudia Gonzáles, de 20 años de edad, trabajadora de una empresa maquiladora, quien desapareció el 10 de octubre de 2001.

Frente a su desaparición, sus familiares presentaron las respectivas denuncias ante las autoridades correspondientes. Sin 
embargo, dichas autoridades no realizaron mayor esfuerzo en las investigaciones, limitándose únicamente a elaborar carteles, un registro de su desaparición y dentro del expediente a tomar versiones y a delegar la investigación a la policía judicial mexicana.

Posteriormente, casi un mes después, el 6 de noviembre de 2001 se encontraron los cuerpos de Claudia, Esmeralda y Laura, con signos de violencia sexual y con claros indicios de que previamente a su muerte, estuvieron privadas de su libertad.

Ante esta lamentable situación, los familiares de las víctimas insistieron a las autoridades para que se investigue y se sancione a los responsables. Sin embargo, aquéllo no sucedió. Por este motivo, los familiares se vieron obligados a recurrir a instancias internacionales, puesto que la justicia mexicana hizo casi nada por tales casos, tanto en la desaparición, como en la muerte de las tres mujeres.

Los abogados de los familiares presentaron ante la Comisión Interamericana de los Derechos Humanos la petición de que se declare al Estado mexicano, responsable de la violación de los derechos consagrados en los artículos 4 (derecho a la vida), 5 (derecho a la integridad personal), 7 (derecho a la libertad personal), 8 (garantías judiciales), 19 (derechos del niño) y 25 (protección judicial), en relación con los artículos 1.1 (obligación de respetar los derechos) y 2 (deber de adoptar las disposiciones del Derecho interno) de la Convención Americana sobre Derechos Humanos y con el artículo 7 de la Convención de Belém do Pará.

Los familiares solicitaron, además, que se declare al Estado, responsable porla violación de los artículos 7 y 11 de la Convención 
Americana, todos ellos en relación con los artículos 1.1 y 2 de ésta, así como el artículo 7 de la Convención de Belém do Pará, en conexión con los artículos 8 y 9 del mismo instrumento y la violación del artículo 5 de la Convención Americana en perjuicio de Claudia Gonzáles.

La Corte Interamericana de Derechos Humanos (CIDH), en su análisis dentro de la sentencia emitida, examina varios aspectos y temas trascendentales, empezando por el importante reconocimiento de que los asesinatos de mujeres, suscitados en Ciudad Juárez, son el resultado de una cultura de discriminación presente en la localidad en contra de las mujeres y que, por lo tanto, las tres fueron víctimas de violencia en su contra, según lo establecido en la Convención de Belém do Pará y la Convención Americana, con la particularidad, a criterio de la Corte, que dichos delitos fueron cometidos por cuestiones de género dentro de la esfera social y violenta que se vive en Ciudad Juárez.

La Corte Interamericana reconoce que la justicia mexicana cometió varias irresponsabilidades e irregularidades, empezando desde el manejo de evidencias, la identificación y posterior entrega de los cadáveres de las víctimas, así como también en el retraso injustificado de las investigaciones. Asimismo, indica que en las investigaciones no se consideró el contexto de violencia contra la mujer, en el cual se produjeron las tres ejecuciones y quizá, lo más grave, manifiesta que dentro de la investigación, se construyó y se forjó autores para que estas personas sean los presuntos responsables del delito.

Además, la Corte Interamericana acusa a México de no acatar lo que disponen instrumentos internacionales, tales como la Convención Americana y la Convención Belém do Pará, 
respecto a la implementación, por parte de los Estados de normas o medidas necesarias ante la desaparición de personas, e indica, igualmente, que no se evidencia que dicho Estado ha trabajado en la prevención, investigación y sanción en los casos de violencia contra la mujer.

En virtud de lo señalado, el Tribunal de la Corte Interamericana considera que, efectivamente se vulneró el derecho de los familiares al acceso a la justicia para que ésta sea eficaz y capaz de protegerlos, especialmente el derecho, tanto de la familia, como de la sociedad de conocer la verdad de lo acontecido. Indica, además, que con la omisiva investigación, se hizo evidente el incumplimiento, por parte del Estado, de la garantía hacia los derechos de la libertad, integridad personal y de la vida de las víctimas, vulnerando de esta manera los derechos de acceso a la justicia y protección judicial, consagrados en los artículos 8.1 y 25.1 de la Convención Americana sobre Derechos Humanos, en relación con los artículos 1.1 y 2 de ésta y 7.b y 7.c de la Convención de Belém do Pará.

Pero quizá lo más transcendental de la sentencia, en el caso Campo Algodonero, es el abordaje que la Corte realiza, respecto al ESTEREOTIPO DE GÉNERO, indicando que éste es una preconcepción de atributos o características poseídas o papeles que son o deberían ser ejecutados por hombres y mujeres respectivamente ${ }^{19}$; esta afirmación es dada como respuesta a que dentro de la investigación, se evidenció que las autoridades mexicanas, particularmente miembros de la policía judicial,

19 Véase CIDH. "Estereotipo de género". Disponible en la siguiente página web: http://www.corteidh.or.cr/docs/casos/articulos/ seriec_205_esp.pdf. (última consulta el 3 de noviembre de 2019) 
realizaron por varias ocasiones juicios de valor negativos en contra de las mujeres desaparecidas.

Ante lo cual, la Corte concluyó que la creación y el uso de estos estereotipos, se convierte en una de las causas y consecuencias de la violencia de género en contra de la mujer, constituyéndose así en una manera de discriminación, por lo que con aquella actuación, el Estado mexicano vulneró el deber de no discriminación, contenido en el artículo 1.1 de la Convención Americana.

En razón de todo lo expuesto, el Tribunal de la CIDH considera que en el caso Campo Algodonero, el Estado mexicano, con su acción y omisión, vulneró derechos que se encuentran resguardados, tanto por la Convención Americana, como por la Convención de Belém do Pará, en perjuicio de las víctimas y de sus familiares, siendo estos los derechos a la vida, integridad personal y libertad personal, en relación con la obligación general de garantía. Asimismo, desacató la obligación de adoptar disposiciones de Derecho interno para el cumplimiento de los instrumentos internacionales.

México incumplió con su deber de investigar -y con ello su deber de garantizar- los derechos a la vida, integridad personal y libertad personal de las víctimas junto con los derechos de acceso a la justicia y protección judicial, vulnerando, además, los derechos de los niños.

En perjuicio de los familiares de las tres mujeres, vulneró el derecho a la integridad personal, por los sufrimientos y hostigamientos, causados por parte de las autoridades. 
Por lo expuesto y como mecanismo de reparación, el Tribunal de la Corte Interamericana de Derechos Humanos dispuso que el Estado mexicano dé cumplimiento con lo siguiente:

1. Investigar y sancionar el homicidio de las tres mujeres e incluir en dicha investigación una perspectiva de género; emprender líneas de investigación específicas respecto a violencia sexual tomando en consideración los patrones de Ciudad Juárez.

2. Investigar y sancionar a los funcionarios acusados de irregularidades.

3. Publicar en varios medios escritos mexicanos de amplia circulación la sentencia, realizar además un acto público de reconocimiento de responsabilidad internacional en honor a la memoria de Laura Monárrez, Esmeralda Monreal y Claudia González y levantar un monumento en memoria de las mujeres víctimas de homicidio por razones de género en Ciudad Juárez.

4. Estandarizar protocolos, y demás instrumentos útiles para la investigación de todos los delitos que se relacionen con desapariciones, violencia sexual y homicidios de mujeres, conforme a los estándares internacionales de búsqueda de personas desaparecidas, con base en una perspectiva de género.

5. Crear una página electrónica que contenga la información personal de todas las mujeres desaparecidas en Chihuahua desde 1993. 
6. Capacitar a los funcionarios públicos mexicanos en programas y cursos permanentes de educación y capacitación en derechos humanos y género; perspectiva de género para la debida diligencia en la conducción de averiguaciones previas y procesos judiciales relacionados con discriminación, violencia y homicidios de mujeres por razones de género, y superación de estereotipos sobre el rol social de las mujeres dirigidos.

7. Indemnizar económicamente a los familiares demandantes de las tres víctimas y brindarles atención médica y psicológica.

\section{La tipificación bifurcada del femicidio/feminicidio en Latinoamérica}

A raíz de lo suscitado en el caso Campo Algodonero, México decidió tomar la batuta y proponer la creación de un tipo penal en específico, que sancione la muerte de mujeres, sin embargo y paradójicamente, no fue el primer país en conseguir que se lo incluya como delito dentro de su legislación sustantiva penal.

Fue Costa Rica, quien en abril de 2007, mediante la Ley de Penalización de la Violencia Contra las Mujeres, se convirtió en el primer país, a nivel mundial, en tipificar el homicidio de mujeres como femicidio; año seguido, es decir, en mayo de 2008, Guatemala, mediante la creación de una ley especial, la Ley Contra el Femicidio y otras Formas de Violencia Contra la Mujer la incluyó en su legislación; lo mismo sucedió dos años después en El Salvador, mediante la Ley Especial Integral para una Vida Libre de Violencia para las Mujeres, creada en el 2010 
y puesta en vigencia desde el 2012, sin embargo, en dicho país, se utilizó, particularmente la denominación de feminicidio; y, en Nicaragua, país donde, mediante la Ley Especial Integral contra la Violencia hacia las Mujeres, se lo tipificó como delito de femicidio.

En el caso de México, es importante mencionar que en la sentencia de Campo Algodonero, la Corte no sugirió que se tipificara este delito, no obstante, un año después, en el 2010, el Comité de Derechos Humanos habría de recomendar su tipificación ${ }^{20}$. Fue en abril de 2012 cuando se lo incluyó y tipificó dentro del Código Penal Federal Mexicano, atravesando coyuntural y coincidencialmente con el momento electoral de las elecciones presidenciales, siendo uno de los proponentes, Enrique Peña Nieto, quien, posteriormente, fue el ganador de la contienda presidencial.

Mientras tanto, en los países del Cono Sur, Chile fue el primero que incorporó el delito de femicidio en su Código Penal y exactamente un año después, en diciembre de 2011, Perú decidió incluirlo como delito de feminicidio.

\section{El femicidio en el Ecuador: línea de tiempo histórica-jurídica}

En el Ecuador, en la década de los noventa, se implementó la Ley Contra la Violencia de la Mujer y la Familia, con la cual se comenzó a sancionar las agresiones suscitadas dentro del ámbito familiar. Posteriormente, en el año 2005, el Congreso Nacional, de ese entonces, realizó reformas al Código Penal, con la finalidad de mejorar y ampliar el abanico de delitos sexuales y su sanción,

20 Toledo, P. 2013, p. 19. 
mientras que en el año siguiente, se aprobó el Código de la Salud, con el objetivo de precautelar la salud sexual y reproductiva de las mujeres ecuatorianas.

A partir del año 2007, como política estatal se crearon instituciones públicas para que sean éstas las encargadas de la temática de violencia de género y, posteriormente, el tratamiento del femicidio. Entre esas instituciones, se encontraban el Consejo Nacional de Mujeres (CONAMU) y la Dirección Nacional de Género (DINAGE), siendo el primero el rector en políticas de género, mientras que la segunda, la encargada de coordinar y controlar las Comisarias de la Mujer y la Familia.

De igual manera, en el año 2007, se declaró como política de Estado la ejecución del Plan para la Erradicación de la Violencia de Género, mediante la expedición del Decreto Ejecutivo 620 de ese mismo año. Posteriormente en el año 2008, en la Constitución Política de la República del Ecuador se incluyó, en su artículo 66, la garantía de las personas para su desarrollo físico, sexual, respeto de integridad personal y, en general, al desarrollo de una vida libre de violencia, sea en el ámbito público o privado.

Este apartado del cuerpo legal dispuso, además, que sea el Estado el que garantice todas las medidas y mecanismos, tendientes a prevenir, eliminar y sancionar toda forma de violencia, en especial la ejercida contra mujeres, niñas, niños y adolescentes, personas adultas mayores y personas con discapacidad ${ }^{21}$.

Con la base constitucional establecida, años más tarde el Estado ecuatoriano formuló el Plan Nacional del Buen Vivir 2013-2017,

21 Reyes, C. 2018, p. 15. 
dentro del cual, en el objetivo número 6 se hizo constar: Consolidar la transformación de la justicia y fortalecer la seguridad integral en estricto respeto a los Derechos Humanos ${ }^{22}$, marcando así las líneas de acción, ante diferentes problemáticas de ese entonces, que afectaban a la seguridad integral ciudadana y que iban desde la delincuencia común, organizada y transnacional, inseguridad vial, hasta violencia de género en todas sus formas y violencia contra niñas, niños y adolescentes.

Es importante mencionar que dentro de este plan, se marcó una diferencia sustancial en el tratamiento y el abordaje de la violencia de género como delito, distinguiéndose del resto de delitos, que se encuentran dentro de la delincuencia común.

En el Plan Nacional del Buen Vivir 2013-2017, en la sección correspondiente a la temática de La violencia de género en todas sus formas se hizo constar información estadística, aportada por el Instituto Nacional de Estadísticas y Censos (INEC), la Secretaría Nacional de Planificación y Desarrollo (senPlades), la Policía Nacional, el Ministerio del Interior del Ecuador y el Observatorio Hemisférico de Seguridad, con la cual aparentemente se justificaba en cifras y, de cierto modo, la necesidad de la creación y la tipificación del femicidio como delito.

En dicha información, se mencionaban datos importantes, tales como que en el año 2012, según la estadística presentada por SENPLADES, los homicidios a mujeres representaron el $12 \%$ del total de homicidios a nivel nacional, un $4 \%$ más que lo ocurrido en el año 2008; mientras que la tasa de homicidios de 3 mujeres

22 Secretaría Nacional de Planificación y Desarrollo(SenPlades). Plan Nacional del Buen Vivir 2013-2017. 2013. 
fallecidas por cada 100 mil habitantes en el Ecuador, no había manifestado reducciones importantes en los últimos años a diferencia de la tasa de homicidios en general $^{23}$.

\section{Gráfico 1}

Evolución del homicidio femenino en el Ecuador (2007-2012)



\section{Fuente: Policía Nacional del Ecuador}

Asimismo, se mencionó que en el año 2010, la Comisión de Transición hacia el Consejo de las Mujeres y la Igualdad de Género mostró como resultados que del $100 \%$ de homicidios cometidos en contra de mujeres, el 93,8\% fueron femicidios o existió la sospecha de haberlos sido y que, de ellos, el $66 \%$ fueron cometidos por parejas o ex parejas.

23 Secretaría Nacional de Planificación y Desarkollo(Senplades). 2013, p. 10. 
Esta misma cartera de Estado aseveraba, entonces que: No se puede establecer el dato exacto respecto de feminicidios, debido a la ausencia de una metodología única ${ }^{24}$.

\begin{abstract}
Al respecto, Lita Martínez, integrante del Centro de Atención y Ayuda para la Mujer (CEPAM-Guayaquil), uno de los principales promotores de la tipificación del femicidio en el Ecuador como delito manifiesta que: Tipificar al femicidio permite que pueda ser evidenciado y sancionado. No es otra cosa más que evidenciar las muertes que son palpables ${ }^{25}$.
\end{abstract}

Con este antecedente y posterior al asesinato de la quiteña Karina Del Pozo, la Asamblea Nacional del Ecuador y como una reacción a la presión mediática de las redes sociales, de colectivos y organizaciones de defensa de las mujeres, decidió poner a debate el tema del femicidio para su posterior tipificación e inclusión en el naciente Código Orgánico Integral Penal, el cual, en ese entonces, se encontraba en pleno trámite.

Es así que, incluso, el presidente del Consejo de la Judicatura, de ese entonces, a reglón seguido y como un aparente y gran aporte estatal para erradicar la violencia de género, mencionaba durante la conmemoración del Día Internacional para la Eliminación de la Violencia contra la Mujer, realizada el 25 de noviembre de 2015, que: Uno de los logros más importantes alcanzados en los últimos años es la tipificación del delito de femicidio en el

\footnotetext{
24 Ibíd.

25 BBC Mundo. “Entrevista concedida a Lita Martínez", el 21 de octubre de 2019. Disponible en la siguiente página web: http:// www.bbc.com.
} 
Código Orgánico Integral Penal (COIP) ${ }^{26}$. Por todo lo expuesto, a nivel de las esferas estatales e, incluso, para varios de los movimientos feministas y Organizaciones No Gubernamentales (ONGS), quienes dicen defender y buscar la protección de las mujeres y sus derechos, el gravísimo problema de la violencia de género (a la cual considero debería separársela y distinguírsela de la violencia intrafamiliar y contra la mujer) había sido resuelto que las mujeres dejarían de morir en manos de sus esposos o convivientes $\mathrm{y}$, por lo tanto, el Derecho penal sería, con su drástica pena simbolizada en años, el instrumento ejemplificador de la sociedad.

\section{Tipificación del delito de femicidio y las estadísticas de muerte de mujeres en el Ecuador}

En el Código Orgánico Integral Penal ecuatoriano aparecieron varias novedades, entre las cuales se encontraba justamente la incorporación del femicidio en dicha normativa. Sin embargo y antes de que el femicidio llegara al país, la tendencia, como se mencionó anteriormente, comenzó en México, con la creación de la Ley General de Acceso de las mujeres a una vida libre de violencia, mientras que en Costa Rica, se originó la Ley de Penalización de la violencia contra las mujeres y en Guatemala apareció la Ley contra el Femicidio y otras formas de violencia contra la mujer.

26 Discursodel presidentedelConsejodelaJudicaturaenlaconmemoración por el Día Internacional para la Eliminación de la Violencia contra la Mujer, de 25 de noviembre de 2015. Véase la siguiente página web: http://www.funcionjudicial.gob.ec/index.php/es/saladeprensa/noti cias/item/2463-gustavo-jalkh-\%E2\%80 \%9Cerradicar-la-violencia-deg\%C3\%A9nero-es-un-trabajo-de-todos\%E2\%80\%9D.html. (última consulta el 19 de octubre de 2019) 
En El Salvador y Chile, en el 2010, aparecieron, respectivamente, la Ley Especial Integral para una Vida libre de violencia para las mujeres, la Ley de modificación del Código Penal y la Ley 20.066 sobre Violencia intrafamiliar, estableciendo el femicidio, aumentando las penas aplicables a este delito y reformando las normas sobre parricidio.

En Perú, en el 2011, se legisló la Ley 29819, la cual modifica el artículo 107 del Código Penal, incorporando el feminicidio, lo propio en Nicaragua, en el año 2012, con la creación de la Ley Integral contra la Violencia hacia las mujeres y de reforma a la Ley 641.

Finalmente, la tendencia llegó al Ecuador, donde justamente en el año 2012, se trataba en la palestra política y legislativa la creación de un nuevo Código penal, siendo inclusive en ese año en el que se producía en la Asamblea Nacional el primer debate del Código Orgánico Integral Penal; luego en el 2013, se produjo el segundo debate; y, el 28 de enero de 2014 se lo aprobó.

Pocos días después, el lunes, 10 de febrero de 2104, se publicó en el Registro Oficial N. . 180 , este nuevo instrumento de la normativa penal ecuatoriana, el cual entraría en vigencia 180 días posteriores a su publicación en el mencionado Registro, es decir, su aplicabilidad en el campo penal y procesal ecuatoriano sería a partir del 10 de agosto de 2014.

Es a partir de esta fecha que se tienen datos oficiales de las muertes de mujeres en el Ecuador, siendo así que en el año 2018, el INEC publicó el texto denominado Atlas de Género, en el cual se incluyen varios datos estadísticos oficiales, entre los que se encuentran los casos de femicidio en el mencionado país, suscitados desde agosto de 2014 hasta diciembre de 2017. 
En dicho documento se detalla el número de femicidios presentes en cada provincia y a nivel nacional, información importante que se encuentra tabulada de la siguiente manera:

Tabla 1. Femicidios en el Ecuador

\begin{tabular}{|l|c|c|c|c|}
\hline PROVINCIA & $\mathbf{2 0 1 4}$ & $\mathbf{2 0 1 5}$ & $\mathbf{2 0 1 6}$ & $\mathbf{2 0 1 7}$ \\
\hline Azuay & 0 & 2 & 3 & 9 \\
\hline Bolívar & 0 & 0 & 1 & 2 \\
\hline Cañar & 0 & 1 & 2 & 1 \\
\hline Carchi & 0 & 0 & 0 & 0 \\
\hline Cotopaxi & 1 & 0 & 0 & 6 \\
\hline Chimborazo & 1 & 3 & 0 & 4 \\
\hline El Oro & 1 & 3 & 4 & 5 \\
\hline Esmeraldas & 1 & 2 & 1 & 6 \\
\hline Guayas & 4 & 7 & 14 & 15 \\
\hline Imbabura & 1 & 1 & 4 & 1 \\
\hline Loja & 0 & 2 & 4 & 2 \\
\hline Los Ríos & 1 & 2 & 3 & 8 \\
\hline Manabí & 2 & 7 & 6 & 11 \\
\hline Morona Santiago & 0 & 0 & 0 & 0 \\
\hline Napo & 5 & 0 & 0 & 0 \\
\hline Pastaza & 3 & 3 & 2 & 4 \\
\hline Pichincha & 0 & 0 & 0 & 1 \\
\hline Tungurahua & 0 & 0 & 0 \\
\hline Zamora Chinchipe & 1 & 0 & 0 \\
\hline Galápagos & 0 & 17 & 24 \\
\hline
\end{tabular}




\begin{tabular}{|l|c|c|c|c|}
\hline PROVINCIA & $\mathbf{2 0 1 4}$ & $\mathbf{2 0 1 5}$ & $\mathbf{2 0 1 6}$ & $\mathbf{2 0 1 7}$ \\
\hline Sucumbíos & 1 & 2 & 2 & 3 \\
\hline Orellana & 0 & 3 & 1 & 3 \\
\hline Santo Domingo de los Tsáchilas & 4 & 2 & 4 & 1 \\
\hline Santa Elena & 1 & 1 & 1 & 3 \\
\hline & & & & \\
\hline TOTAL & $\mathbf{2 7}$ & $\mathbf{5 5}$ & $\mathbf{6 9}$ & $\mathbf{1 0 9}$ \\
\hline
\end{tabular}

Fuente: Instituto Nacional de Estadísticas y Censos (INEC)

De la información proporcionada por el INEC (2018) y proyectada en un gráfico estadístico como en el que se encuentra a continuación, se hacen evidentes datos importantes, útiles y prácticos, que permiten realizar las siguientes representaciones gráficas:

\section{Gráfico 2. Femicidios en el Ecuador detallados por año}

\section{FEMICIDIOS POR AÑo}



Fuente: Instituto Nacional de Estadísticas y Censos (INEC) 
La mayor cantidad de muertes de mujeres ecuatorianas durante los años 2014, 2015, 2016 y 2017 se han producido en una provincia de la Sierra y dos provincias de la Costa, siendo Pichincha, con 59 casos, la provincia con el mayor número de femicidios en los cuatro años analizados, seguido por Guayas, con 40 casos, y muy por debajo Manabí, con 26 casos.

\section{Gráfico 3. Femicidios en el Ecuador detallados por provincia}

\section{Femicidios 2014-2017 (Provincias)}

60
40
20
0

Fuente: Instituto Nacional de Estadísticas y Censos (INEC)

Similar situación se evidencia, si los femicidios son clasificados y representados por regiones como se observa en el siguiente gráfico, la región interandina es la que mayor número de muertes femeninas presenta, con 133 casos en los cuatro años, la Costa le sigue, con 109 casos, muy por debajo la Región Amazónica, con 18, mientras que en la Región Insular, no se produjeron muertes por el delito de femicidio en los años analizados. 
Gráfico 4. Femicidios en el Ecuador detallados por región

\section{Femicidios 2014-2017 (Regiones)}

Oriente

Sierra
0

Fuente: Instituto Nacional de Estadísticas y Censos (INEC)

Como se ha mencionado anteriormente, la información proporcionada por el INEC, en el 2018, a través de su texto, denominado Atlas de Género, permite precisamente confirmar que la tipificación de delitos como herramienta de prevención, de manera general dentro de una sociedad, no siempre se cumple, ni tampoco es eficaz, ni efectiva. 
Gráfico 5. Delitos contra la vida vs. Femicidios



Fuente: Fiscalía General del Estado

Con lo expuesto en el gráfico y sus datos, se hace evidente una situación criminológica particular, puesto que mientras la totalidad de los delitos contra la vida, entre los que se encuentran comprendidos: asesinatos, homicidios y sicariato, disminuyen de manera paulatina en los 3 años posteriores al COIP, el femicidio, por su parte, ha ido en aumento.

Tabla 2. Delitos contra la vida y femicidios en los años 2015 al 2017

\begin{tabular}{|c|c|c|}
\hline & $\begin{array}{c}\text { Delitos contra la vida } \\
\text { (asesinato, homicidio y sicariato) }\end{array}$ & Femicidio \\
\hline $\mathbf{2 0 1 5}$ & 1000 & 55 \\
\hline $\mathbf{2 0 1 6}$ & 890 & 69 \\
\hline $\mathbf{2 0 1 7}$ & 861 & 108 \\
\hline
\end{tabular}

Fuente: Fiscalía General del Estado 
Los datos expuestos, tanto en la tabla, como en el gráfico ponen en tela de duda una de las falacias jurídicas, criminológicas y feministas, con las que se ha pretendido justificar la tipificación del femicidio, en la cual se menciona que creando delitos, específicamente, que sancionen la muerte de las mujeres, su vida estará protegida y la violencia intrafamiliar y/o contra la mujer se reduciría.

En similar sentido, dicha información hace tambalear también a otra de las falacias jurídico feministas, la misma que al estilo cortina de humo, manifiesta que la tipificación del femicidio responde a obligaciones adquiridas por el Estado ecuatoriano, al ser éste suscriptor de instrumentos internacionales como la Convención Interamericana para Prevenir, sancionar y erradicar la violencia contra la mujer, o mejor conocida como la Convención de Belém do Pará, la cual en su artículo número 7 al hablar de los deberes que tienen los Estados para prevenir, sancionar y erradicar la violencia contra la mujer, tienen que adoptar varios de los siguientes mecanismos:

b. Actuar con la debida diligencia para prevenir, investigar y sancionar la violencia contra la mujer;

c. Incluir en su legislación interna normas penales, civiles y administrativas, así como las de otra naturaleza que sean necesarias para prevenir, sancionar y erradicar la violencia contra la mujer y adoptar las medidas administrativas apropiadas que sean del caso;

d. Adoptar medidas jurídicas para conminar al agresor a abstenerse de hostigar, intimidar, amenazar, dañar o poner 
en peligro la vida de la mujer de cualquier forma que atente contra su integridad o perjudique su propiedad;

f. Establecer procedimientos legales justos y eficaces para la mujer que haya sido sometida a violencia, que incluyan, entre otros, medidas de protección, un juicio oportuno y el acceso efectivo a tales procedimientos;

g. Establecer los mecanismos judiciales y administrativos necesarios para asegurar que la mujer objeto de violencia tenga acceso efectivo a resarcimiento, reparación del daño u otros medios de compensación justos y eficaces.

Como se puede observar en los principales literales transcritos de la Convención de Belém do Pará, todos son medios que se enfocan precisamente en prevenir la violencia contra la mujer $\mathrm{y}$, sobretodo, evitar que se llegue al mayor acto de violencia en su contra como es el que ella pierda su vida. Sin embargo, al relacionarlos con la realidad particular que se presenta en los delitos de femicidio, algo no coincide.

Es así que podría realizarse un breve análisis, indicando, por ejemplo, que el literal b) refiere principalmente a la debida diligencia que debe existir en el trámite. Por otro lado, por más grandes esfuerzos que realice el gobierno de turno para agilitar y modernizar al aparataje judicial, el sistema penal siempre será lento, engorroso, letárgico e incluso, en ocasiones, hasta poco efectivo en la respuesta que éste otorgue no solo a las víctimas de violencia, sino a las víctimas en general.

Al literal c) se lo podría entender como aplicado de manera parcial en el país, puesto que se ha incluido en la normativa penal un nuevo 
delito llamado femicidio, de ahí que tenga el resultado deseado, como se ha mencionando anteriormente, es bastante cuestionable.

Los literales d) y f) se refieren, exclusivamente, a las medidas de protección para la mujer, víctima de violencia, las cuales efectivamente constan en el articulado del corp y que van desde la emisión de boletas de auxilio, hasta la salida del agresor del domicilio, entre otras; lo cuestionable es que éstas muchas veces quedan cortas, frente a la situación de violencia que atraviesa la víctima, puesto que en la mayoría de los casos en los que las mujeres han fallecido, se les ha encontrado en su poder dichas boletas emitidas con anterioridad, indicio lamentable que muestra, claramente, que la respuesta penal, judicial, policial y estatal, en general, no es la más efectiva frente a tal problemática.

Y, finalmente, el literal g), el cual se enfoca hacia la reparación integral de la víctima, quien ha sufrido violencia. No obstante, si se sobreentiende, como sucede en la práctica judicial en el Ecuador, al femicidio como el último peldaño en la escalera de violencia, la reparación sería algo ya fuera de lugar, pues, parafraseando a ZAFFARONI, de nada sirve el femicidio como delito, si la vida de la mujer ya se encuentra acabada.

\section{La tipificación del delito de femicidio en el Código Orgánico Integral Penal como mecanismo de prevención}

El discurso de las autoridades en el Ecuador del 2014 y 2015, encabezado en ese entonces por José Serrano, en su calidad de Ministro del Interior y Policía y Gustavo Jalkh, presidente del Consejo de la Judicatura, se vanagloriaba como una gran conquista, en su aparente lucha contra la violencia de género, 
la tipificación del delito de femicidio y el efecto que éste tendría como mecanismo de prevención social.

Incluso Serrano quiso ir más allá de su rol político y tomó curiosamente un papel activo y protagónico en el conocido Caso Sharon al manifestar, mediante su cuenta de Twitter, su descontento con la sentencia de 2 años de pena privativa de libertad, que recibía por homicidio culposo, Geovanny López, ex conviviente de la cantante, por lo cual solicitó por esa misma red social al Consejo de la Judicatura, presidido por Jalkh, se tomen las medidas disciplinarias correspondientes con los jueces que emitieron dicha sentencia.

El desenlace del caso ya es conocido públicamente: los jueces destituidos y Geovanny López, sentenciado increíblemente por segunda vez y por el delito de femicidio.

En relación a este caso, años más tarde, es decir, en abril del 2019, Víctor Rivadeneira, ex asesor de José Serrano, presentó una denuncia en contra de su ex jefe, por el presunto delito de tráfico de influencias justamente dentro del Caso Sharon, ya que, según Rivadeneira: Serrano y Jalkh se valieron de sus posiciones de poder para conseguir una condena por femicidio, por cuanto el afán de la sentencia fue marcar un precedente, imponiendo la primera sentencia por femicidio, delito recién tipificado en el Código Orgánico Integral Penal ${ }^{27}$.

Es justamente ese precedente ejemplificador como paradigma lo que se quería conseguir, con la judicialización de los casos de

27 Diario El Telégrafo. "Entrevista a Víctor Rivadeneira", versión digital, 17 de abril de 2019 . 
femicidio en el Ecuador, o lo que la doctrina reconoce con el nombre de la prevención general de la pena.

En el artículo 52 del Código Orgánico Integral Penal ecuatoriano se incluyó como la finalidad de la pena, literalmente, la prevención general para la comisión de delitos, así como también en dicho artículo se hace referencia a la pena entendida como reparación del derecho de la víctima y al desarrollo -aunque sea utópico- de las capacidades y los derechos de los sentenciados.

El Legislador, en el artículo citado, hizo constar las 3 teorías doctrinarias de la pena: la teoría de la retribución, la teoría de la prevención específica y la teoría de la prevención general, siendo esta última la que mayormente se relaciona con el tema del femicidio.

La teoría de la prevención general fue creada por el alemán PAUL Johann Anselm V. FeUERBACh, quien actualmente es considerado como el fundador de la ciencia moderna del Derecho penal de su país.

Para la teoría de la prevención general, la pena debe actuar no especialmente sobre el condenado -como ocurre en la teoría de la prevención especial-, sino que debe de actuar sobre la comunidad en su conjunto. Es decir, sostiene que el advertir o amenazar a la comunidad en general, sobre las consecuencias de hacer o dejar de hacer determinada acción, que se encuentra conminada con sanción (penal), debe propiciar la conciencia social en la comunidad de que al transgredir dicha conminación, se estará inmerso en la persecución y posterior represión del Estado, a través del ejercicio del iuspuniendi ${ }^{28}$.

28 GómEz. 2016, p. 162, 
Además, la doctrina determina que la prevención general tiene que cumplir con 3 finalidades:

1) El aprendizaje, mediante la sensibilización pedagógica que el Legislador realiza, a través de la tipificación de los delitos;

2) El ejercicio confiable del Derecho, que se materializa, mediante la actividad propia del Derecho penal; y,

3) La pacificación como efecto cuando la conciencia social y jurídica se tranquiliza, esto como consecuencia de la sanción que recibe el agresor de la norma penal y la solución del conflicto Estado-persona procesada.

Por lo tanto, se puede concluir, en términos esenciales, que la prevención general lo que pretende es prevenir la futura comisión de conductas punibles, es decir, delitos; sin embargo, la distancia entre este postulado teórico y la realidad práctica ecuatoriana es abismal.

Es más, la tipificación no solo del femicidio, sino de varios delitos, con justificación en este fin, así como también el aumento en la gravedad de la pena no han servido como mecanismo de prevención y, por ende, no se ha consolidado como una herramienta eficaz, ni tampoco como ese anhelado precedente ejemplificador. 


\section{Derecho penal del enemigo en el Código Orgánico Integral Penal}

El Derecho penal del enemigo fue un concepto propuesto por el profesor alemán GüNTHER JAKOBS, en la década de los años ochenta, sin embargo y en ese entonces, sus postulados no tuvieron mayor acogida, incluso ni siquiera por parte de sus propios colegas, puesto que a varios de ellos, su propuesta teórica les pareció demasiado extrema al punto que se comentó que aquel Derecho penal, terminaba deshumanizando totalmente al adversario y convirtiéndolo en el diferente.

Es a partir del año 2001, que se produce un segundo auge, sin embargo ahora con una aparente justificación: el atentado al Wall Street Center, en Estados Unidos de América, suscitado el 11 de septiembre del 2001, hecho con el cual se promulgó su reaparición, ya que varios penalistas se sintieron incitados y tentados para que el concepto vuelva a la palestra del campo del Derecho penal.

Y, en efecto, volvió actualmente, con la singularidad que esta doctrina podía ser enfocada en varios temas/problemas sociales, caracterizándose por las siguientes particularidades:

a) Se construye un Otro a quien reprochar la violencia y sobre quien se estructuran criterios de peligrosidad; $y$,

b) Se excepciona su régimen jurídico de persona, al negársele algunas de las garantías judiciales, tanto en la fase sustantivo-penal (más agravantes abstractas y delitos sin estricta legalidad), como en la procedimental (juicios rápidos y sin contradicción) y 
las penitenciarias (no indultos o amnistías y vigilancia punitiva ex post condena $)^{29}$.

Por lo tanto, el Derecho penal del enemigo ve al sujeto no como persona, sino como una fuente de peligro -como si fuera un animal peligroso- como un otro y/o un sujeto diferente, sospechoso $\mathrm{y}$, por ende, con un pronóstico negativo de difícil y casi imposible reinserción social; razones por las que incluso se llega a justificar las restricciones o limitaciones de derechos fundamentales.

Este tipo de Derecho penal se contrapone al Derecho penal del ciudadano, puesto que este último, sanciona al sujeto por ser él quien comete el delito, sin prestar mayor atención al antecedente o pronóstico futuro del infractor, pero, sobre todo, es importante resaltar que el Derecho penal del ciudadano, funciona apegado al sistema garantista, que tanto protege la Constitución del Ecuador.

Sin embargo, en el Código Orgánico Integral Penal y en consideración a todo lo arriba mencionado, uno de aquellos enemigos al parecer es el sujeto activo del artículo 141, en el que se encuentra tipificado el femicidio, puesto que incluso se lo podría llegar a ver como un delito dirigido indirecta y exclusivamente al hombre, en calidad de enemigo.

Las instancias internacionales también han sido tentadas por el Derecho penal del enemigo, tal como se puede evidenciar en la jurisprudencia de la Corte Interamericana de Derechos Humanos, en los casos Almonacid vs. Chile o La Cantuta vs. Perú; casos en los cuales se llegó a excepcionar incluso principios como el non

29 JAKOBS, G. 2006, pp. 93-116. 
bis in ídem, la irretroactividad de la ley penal in bonam partem del procesado o el plazo razonable $e^{30}$, todo esto con la aparente justificación y finalidad de llegar a conseguir una sentencia.

\section{Las falacias jurídicas feministas: mentiras que perjudican a quien dicen defender}

El reproche en contra de la violencia no debe estar enmarcado por particularidades como género, etnia, religión y nacionalidad por lo que éste tiene que ser absoluto y no hallarse centralizado o reducido a una sola causa o a una mala llamada lucha de género, la cual a pesar de que en el Ecuador ha conseguido aparentes logros legales, tales como la tipificación del delito de femicidio y el aumento de la punibilidad de la violencia de género; estos mencionados logros, lamentablemente, lo que han conseguido es empeorar precisamente la situación de quien, como movimiento, dicen defender: las mujeres.

El femicidio como delito y, por ende, como un instrumento penal, en sus más de 5 años de vigencia, no ha conseguido generar el resultado y la eficacia pretendida en la reducción de muertes, puesto que si en el 2014 lamentablemente murieron 27 mujeres, en el año 2017 esa cifra llegó a casi cuadriplicarse, llegando a 97 el número de víctimas fatales ${ }^{31}$.

Similar situación sucede con el agravamiento en la punibilidad de la violencia contra la mujer, puesto que si bien es cierto la pena de la infracción contravencional en el 2014 era menor, dentro del campo procesal su trámite y, por tanto, su respuesta

\footnotetext{
30 Malarino, E. 2010, pp. 45-48.

31 Instituto Nacional de Estadísticas y Censos (INEC). 2018, p. 361.
} 
estatal al ser una contravención, era mucho más ágil y rápida con las extinguidas Comisarías de la Mujer, e incluso vale la pena resaltar, también, que el acceso al sistema judicial para las usuarias, era mucho más fácil y sencillo.

Por lo tanto, algunas figuras legales de aparente avanzada y vanguardistas, entre ellas, obviamente el femicidio y el incremento punitivo terminan siendo falacias jurídicas, que generan el efecto contrario para lo que se dijeron fueron creadas $\mathrm{y}$, por consiguiente, terminan siendo instrumentos utilizados y serviles de un creciente y coyuntural populismo penal.

Por otro lado, hasta el momento y a pesar de que han existido en la sociedad ecuatoriana varios delitos cometidos en contra de mujeres precisamente por otras mujeres, siendo las perpetradoras sus mismas familiares directas, como, por ejemplo, hijas y hermanas, el hecho no ha llegado a ser considerado como delito de femicidio, por lo que cabrá entonces hacer la pregunta: ¿si acaso el delito de femicidio fue creado para exclusivamente sancionar al sujeto activo cualificado como hombre-agresor?

Al respecto, no se puede dejar de mencionar que desde su tipificación, únicamente como sujeto activo en la comisión del delito de femicidio han sido sancionados hombres y que en el año 2018, en 8 de 64 casos reportados, desde enero hasta el 2 de octubre del mismo año, el femicida se suicidó y existen 89 menores en situación de orfandad ${ }^{32}$, datos sobre los cuales ni el movimiento feminista, ni el Estado se han preocupado.

32 Comisión Ecuatoriana de Derechos Humanos (CedHu). 2018. 
Finalmente, y de manera sucinta, hay que señalar que la construcción del femicidio como delito e instrumento de castigo en el Ecuador deviene de la corriente feminista de la tercera ola y una derivación de ésta, el feminismo punitivo, el cual busca, en la particularidad del género, el castigo al hombre a veces, incluso ,yendo más allá del hecho de que, si existan o no pruebas.

Quizás por ello es que con la tipificación del femicidio en el país, no se ha logrado incidir en la reducción de muertes a mujeres, e incluso en varios de los casos que han sido tramitados por este delito, el procedimiento penal o adolece de vicios o las pruebas son insuficientes para inculpar a los presuntos responsables, sin embargo y a pesar de ello, estos continúan cumpliendo su condena. 


\section{BIBLIOGRAFÍA}

ATENCIO, G. "Feminicidio-Femicidio: Un paradigma para el análisis de la Violencia de Género", 2011. Disponible en la siguiente página web: http://feminicidio.net/sites/ default/files/seccion_feminicidio_paper_02.pdf. (última consulta el 1 de noviembre de 2019

BBC MUNDO. "Entrevista concedida a Lita Martínez", 21 de octubre de 2019. Disponible en la siguiente página web: http://www.bbc.com.

CEDHU. "64 mujeres fueron asesinadas en Ecuador desde enero a octubre del 2018”, 2018. Disponible en la siguiente página web: http://www.cedhu.org/noticias/13-noticiascedhu/42-64-mujeres-fueron-asesinadas-en-ecuadordesde-enero-a-octubre-del-2018. (última consulta el 3 de noviembre de 2019)

CIDH. "Estereotipo de género". Disponible en la siguiente página web:http://www.corteidh.or.cr/docs/casos/articulos/ seriec_205_esp.pdf. (última consulta el 3 de noviembre de 2019)

DEVINEAU, J. "Autour du concept de fémicide/féminicide: entretiens avec Marcela Lagarde et Montserrat Sagot", Problèmes d'Amérique Latine. Francia, 2012. 
DIARIO EL TELÉGRAFO. "Ex asesor de José Serrano denuncia tráfico de influencias en caso Sharon", 17 de abril de 2019. Disponible en la siguiente página web: http:// www.eltelegrafo.com.ec/noticias/judicial/12/exasesorjoseserrano-denuncia-traficodeinfluencias-sharon . (última consulta el 2 de noviembre de 2019)

. "Entrevista a Víctor Rivadeneira", 17 de abril de 2019. (versión digital)

DIRECCIÓN NACIONAL DE COMUNICACIÓN DEL CONSEJO DE LA JUDICATURA. "Gustavo Jalkh: Erradicar la violencia de género es un trabajo de todos (con versión Kichwa)", miércoles, 25 de noviembre de 2015. Disponible en la siguiente página web: http://www.funcionjudicial. gob.ec/index.php/es/saladeprensa/noticias/item/2463gustavo-jalkh-\%E2\%80\%9Cerradicar-la-violencia-deg\%C3\%A9nero-es-un-trabajo-de-todos\%E2\%80\%9D. html. (última consulta el 1 de noviembre de 2019)

FAO. "Femicidios en Ciudad Juárez". Disponible en la siguiente página web: http://www.muyinteresante.es/crimen/ articulo/feminicidios-en-ciudad-juarez-931521801477. (última consulta el 3 de noviembre de 2019)

JAKOBS, G. "¿Derecho penal del enemigo? Un estudio acerca de los presupuestos de juridicidad”, Cancio Meliá, y GómezJara (eds.). Derecho penal del enemigo. El discurso penal de la exclusión. Montevideo, B de F, 2006.

LAGARDE, M. "Feminicidio, el último peldaño de la agresión". Disponible en la siguiente página web: http://www. 
mujeresenred.net/spip.php?article141. (última consulta el 23 de septiembre de 2019)

MALARINO, E. “Activismo judicial, punitivización y nacionalización. Tendencias antidemocráticas y antiliberales de la Corte Interamericana de Derechos Humanos", Grupo Latinoamericano de Estudios sobre Derecho Penal Internacional, Sistema Interamericano de Protección de Derechos Humanos y Derecho Penal Internacional. Montevideo, Konrad Adenauer Stiftung y Georg August Universität Göttingen, 2010.

MONÁRREZ, J. "Las diversas representaciones del feminicidio y los asesinatos de mujeres en Ciudad Juárez, 1993- 2005", Violencia contra las mujeres e inseguridad ciudadana en Ciudad Juárez. Ciudad de México, El Colegio de la Frontera Norte y Miguel Ángel Porrúa Editores, 2010.

- Violencia infligida contra la pareja y feminicidio. vol. II. Ciudad de México, El Colegio de la Frontera Norte y Miguel Ángel Porrúa Editores, 2010.

MULIER. "Feminismo", canal de YouTube. 2018. Disponible en la siguiente página web: https:/www.youtube.com/ watch?v=-7mFqtJYaQU. (última consulta el 23 de septiembre de 2019)

RADFORD, J., y Russell, D. Femicide: The Politics of Woman Killing. Nueva York, Twayne, 1992.

REYES, C. "Femicidio e investigación policial. El enfoque de género como imperativo para evitar la impunidad. 
Análisis del año 2015". Trabajo de titulación para obtener la Maestría de Investigación en Seguridad y Defensa. Quito, Facultad Latinoamericana de Comunicación Social, 2018.

RUSSEll, D. "Preface", RUSSELl, D. (ed.). The Politics of Woman Killing. New York, Russell D., 1992.

. Defining Femicide and Related Concepts. New York, Athene Series, Teachers College Press, 2001.

SAGOT, M., y Carcedo, A. Femicidio en Costa Rica: 1990-1999. San José, Instituto Nacional de las Mujeres, 2002.

SENPLADES (Secretaría Nacional de Planificación y Desarrollo). 1. a edición. Quito, 2013.

TOLEDO, P. "Límites y dificultades en la implementación de las recomendaciones de organismos internacionales de derechos humanos sobre la tipificación del feminicidio en México: Primeras leyes y sentencias". Género, Sexualidades y Derechos Humamos. N. . 2, 2013.

VALle, C. Atlas de género. Quito, Instituto Nacional de Estadísticas y Censos (INEC), 2018.

ZAFFARONI, E. "El discurso feminista y el poder punitivo". Las trampas del poder punitivo. El género del Derecho penal. Birgin, Haydée (comp.). Buenos Aires, Editorial Biblós, 2000. 